\title{
Non-falciparum malaria in Dakar: a confirmed case of Plasmodium ovale wallikeri infection
}

\author{
Mamadou A. Diallo ${ }^{*}$, Aida S. Badiane ${ }^{1}$, Khadim Diongue ${ }^{1}$, Awa Deme ${ }^{1}$, Naomi W. Lucchi², Marie Gaye ,

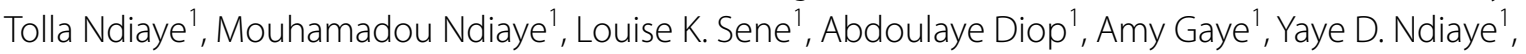 \\ Diama Samb ${ }^{1}$, Mamadou S. Yade ${ }^{1}$, Omar Ndir ${ }^{1}$, Venkatachalam Udhayakumar ${ }^{2}$ and Daouda Ndiaye ${ }^{1}$
}

\begin{abstract}
Background: Plasmodium ovale is rarely described in Senegal. A case of clinical malaria due to P. ovale wallikeri in West Central of Senegal is reported.

Case: A 34-year-old male baker in Dakar, with no significant previous medical history, was admitted to a health clinic with fever and vomiting. Fever had been lasting for 4 days with peaks every $48 \mathrm{~h}$. As monospecific Plasmodium falciparum HRP-2 RDT was negative, he was treated with antibiotics. However, owing to persisting symptoms, he was referred to the emergency unit of the Youssou Mbargane Diop Hospital, Dakar, Senegal. Clinical examination found impaired general condition. All other physical examinations were normal. Laboratory tests showed anaemia (haemoglobin $11.4 \mathrm{~g} / \mathrm{dl}$ ), severe thrombocytopaenia (platelets $30 \times 10^{9} / \mathrm{mm}^{3}$ ), leukopenia $\left(3650 / \mathrm{mm}^{3}\right.$ ), lymphocytopenia $\left(650 / \mathrm{mm}^{3}\right)$. Renal function was normal as indicated by creatininaemia and uraemia ( $11 \mathrm{mg} / \mathrm{l}$ and $0.25 \mathrm{~g} / \mathrm{l}$, respectively) and liver enzymes were slightly elevated (aspartate aminotransferase $77 \mathrm{UI} / \mathrm{I}$ and alanine aminotransferase $82 \mathrm{UI} / \mathrm{l}$ ). Blood smear evaluations in Parasitology Laboratory of Aristide Le Dantec Hospital showed malaria parasites of the species P. ovale with a $0.08 \%$ parasitaemia. Molecular confirmation was done by real time PCR targeting the 18S rRNA gene. The P. ovale infection was further analysed to species level targeting the potra gene and was identified as $P$. ovale wallikeri. According to the hospital's malaria treatment guidelines for severe malaria, treatment consisted of intravenous quinine at hour 0 (start of treatment) and $24 \mathrm{~h}$ after initial treatment, followed by artemether-lumefantrine $24 \mathrm{~h}$ later. A negative microscopy was noted on day 3 post-treatment and the patient reported no further symptoms.
\end{abstract}

Conclusion: Malaria due to non-falciparum species is probably underestimated in Senegal. RDTs specific to non-falciparum species and/or pan specific RDTs should be included as tools of diagnosis to fight against malaria in Senegal. In addition, a field-deployable molecular tool such as the loop-mediated isothermal amplification can be considered as an additional useful tool to detect low malaria parasite infections and for speciation. In addition, national malaria control policies should consider other non-falciparum species in treatment guidelines, including the provision of primaquine for the treatment of relapsing parasites.

Keywords: Plasmodium ovale, Malaria, Fever, RDT, Microscopy, Diagnostic, Treatment, Primaquine, Dakar

\footnotetext{
*Correspondence: mamadoualpha.diallo@ucad.edu.sn

${ }^{1}$ Laboratoire de Parasitologie-Mycologie, Université Cheikh Anta Diop de

Dakar, Avenue Cheikh Anta Diop, Fann, BP 5005, Dakar, Senegal

Full list of author information is available at the end of the article
} and indicate if changes were made. The Creative Commons Public Domain Dedication waiver (http://creativecommons.org/ publicdomain/zero/1.0/) applies to the data made available in this article, unless otherwise stated. 


\section{Background}

Despite the fact that Plasmodium ovale is endemic in tropical Africa, malaria due to $P$. ovale is rarely described in Senegal [1]. The most common pathogen of malaria in Africa is Plasmodium falciparum [2]. In the 1990s, $P$. ovale infections were described in the south of Senegal in the context of the longitudinal study at Dielmo village located $280 \mathrm{~km}$ South East of Dakar [1]. During the first year of the project in 1990, the prevalence of $P$. ovale was determined, among symptomatic and asymptomatic villagers of all groups age, to be $5.5 \%$ either as a mono-infection or as mixed infection with $P$. falciparum [3]. Concerted efforts to control malaria in Senegal contributed to decrease in the overall prevalence of malaria and by 2010 P. ovale infections were rarely reported [1]. Recently, a molecular survey found P. ovale in Kedougou only as mixed infections with $P$. falciparum at $11.5 \%$ of prevalence [4].

Plasmodium ovale consists of two distinct species: $P$. ovale curtisi (classic type) and P. ovale wallikeri (variant type) [5]. The two species are indistinguishable by microscopy but seem to differ in their duration of latency [6]. The recent description of dimorphism in the gene encoding $P$. ovale tryptophan-rich antigen (potra) allows for the distinction between the two $P$. ovale species. Sequence and size variations were noted between the tryptophan-rich antigen genes from $P$. ovale curtisi (poctra) and P. ovale wallikeri (powtra) [5]. This was exploited in a nested PCR detection assay [7], where the species are discriminated by the size of the amplified fragments (299 or 317 bp for poctra; 245 bp for powtra). In addition, Tanomsing et al. developed a semi-nested PCR protocol which efficiently discriminate $P$. ovale wallikeri and $P$. ovale curtisi and found that the 299 bp fragment was overlapping between the two subspecies [8] and the $245 \mathrm{bp}$, represented $P$. ovale wallikeri.

A case of malaria due to P. ovale wallikeri is described in a patient admitted to the emergency unit service of the Youssou Mbargane Diop Hospital of Rufisque, a department of the peripheral region of Dakar in Senegal.

\section{Case presentation}

A 34-year-old male baker living in Diamniadio (Dakar region) sought a consultation at a health centre near his home for fever, headache, vomiting and diarrhoea. Fever had lasted for 4 days with peaks every $48 \mathrm{~h}$. The patient was suspected of malaria and was tested using an HRP-2 based RDT (detecting only P. falciparum). The test was negative for $P$. falciparum malaria and the patient was treated by three intravenous (IV) injection of cefotaxim (third generation of cephalosporin) at $100 \mathrm{mg}$ per $\mathrm{kg}$ per day to cover potential bacterial infection. Owing to persisting symptoms 4 days later, he was referred to the emergency unit of the Youssou Mbargane Diop Hospital, Dakar, Senegal.

The patient had no particular previous medical history. He was born in Thies and moved to Touba at the age 12 and finally at age 23 to Diamniadio, where he has lived since. The patient claimed that he had never been out of these three areas, which are all in West Central of Senegal. Physical examination found impaired general condition but the patient was conscious. Abdomen was tender. All other physical examinations were normal. Another HRP-2 based RDT was performed and was also negative. Other laboratory tests showed anaemia (haemoglobin $11.4 \mathrm{~g} / \mathrm{dl}$ ), thrombocytopaenia (platelets $30 \times 10^{9} / \mathrm{mm}^{3}$ ), leukopaenia $\left(3650 / \mathrm{mm}^{3}\right)$ and lymphocytopaenia $(650 /$ $\mathrm{mm}^{3}$ ). Kidney function was normal as indicated by creatininaemia and uraemia $(11 \mathrm{mg} / \mathrm{l}$ and $0.13 \mathrm{~g} / \mathrm{l}$, respectively). Transaminases were slightly elevated.

Blood smear evaluations in the Parasitology Laboratory of Aristide Le Dantec University Hospital showed malaria parasites in normal and enlarged red blood cells (RBCs). Some infected RBCs were oval shaped and some were fimbriated. However, Schüffner's dots were not observed likely due to staining defect (Fig. 1). All malaria parasite stages (rings, trophozoites, schizonts and gametocytes) were observed. These malaria parasites were identified as P. ovale and a $0.08 \%$ parasitaemia was calculated. Parasite density was measured by determining the ratio of parasites/leucocytes on the basis of 8000 leucocytes/ $\mu \mathrm{l}$ after counting 500 leucocytes. That ratio was found to be 1.1 giving a parasite density of 8800 parasites/ $\mu$ l of blood.

An 18 S rRNA gene real-time PCR molecular assay was undertaken as previously described [9] to confirm the P. ovale, infection (Fig. 2). No others species of Plasmodium was detected. The parasite was then subtyped using the potra gene as target as previously described [7]. This genotyping identified the presence of $P$. ovale wallikeri (Fig. 3).

Based on clinical signs and biological findings, the patient was treated as severe malaria accordingly to the hospital's treatment guideline. Intravenous quinine was given at admission and $24 \mathrm{~h}$ later. $48 \mathrm{~h}$ after initial treatment, oral artemether-lumefantrine was given every $6 \mathrm{~h}$ at six doses. On day 3 after treatment, microscopy was negative and the patient reported no further symptoms. Primaquine was not given (see "Discussion" section).

\section{Discussion}

Plasmodium ovale is a malaria parasite that is endemic in sub-Saharan Africa, although not very commonly described [2]. In Senegal, little attention has been paid to $P$. ovale malaria in the recent years. Here, a case of $P$. ovale infection that appears to have been acquired in Diamniadio, near Dakar, in West Central of Senegal is reported. 

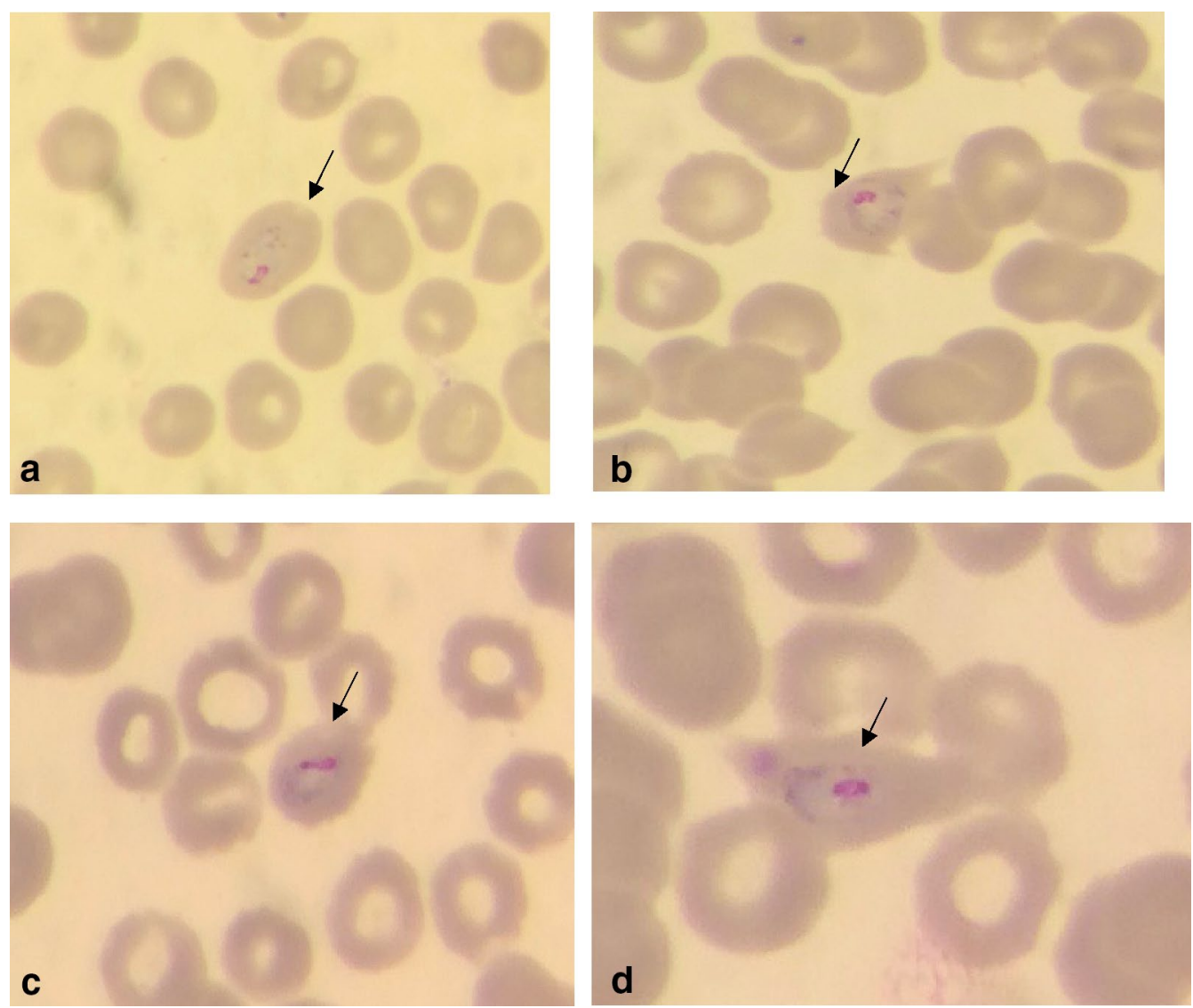

Fig. 1 Giemsa-stained thin blood smears Plasmodium ovale trophozoites in enlarged and ovale shaped red blood cell (a) and with a fimbriated red blood cell (b-d)

This case highlights the need to consider non-falciparum malaria infections in this region for case management. Plasmodium ovale malaria is often mild in clinical presentation [10] and severe forms of the disease are relatively rare [11-13]. The parasite densities are often less than 50 parasites $/ \mu$ land a parasitaemia higher than 5000 parasites $/ \mu$ is rarely reported [14]. This is believed to be due to the fact that $P$. ovale prefers younger RBCs, which are rare in peripheral blood [2]. The patient in this report presented a relatively high density parasitaemia of 8800 parasites $/ \mu$ l and severe thrombocytopaenia. Equally high parasitaemia levels were found in Spanish travellers infected with $P$. ovale wallikeri imported from different countries in Africa and the same study observed that severe thrombocytopaenia was more commonly associated with $P$. ovale wallikeri infection than with $P$. ovale curtisi infections [15]. While the mechanisms that produce thrombocytopaenia in malaria is still not clear it seems likely to be linked to a greater severity of the illness [16].

In Senegal, $P$, ovale subtyping is not documented. Determining the infecting $P$. ovale species may be important because recent observations suggest that the two species might differ in their relapsing patterns [6] and secondly. Plasmodium ovale wallikeri seems to be slightly more pathogenic [15]. The previously described dimorphisms observed in gene encoding $P$. ovale tryptophan-rich antigen (potra) [5] were used to identify the infecting $P$. ovale species as $P$. ovale wallikeri. This is most likely the first time $P$. ovale species determination have been undertaken when describing $P$. ovale infections in Dakar, Senegal.

The patient in this study denied having travelled outside Diamniadio suggesting that the $P$. ovale infection was likely acquired locally. Since Diamniadio is a crossroads town located at the town exit of Dakar where many different human populations from neighbouring regions and countries intersect there are two possible likely sources of the $P$. ovale parasites: (1) from an existing $P$. ovale reservoir in or near Diamniadio, or (2) that the source of the $P$. ovale infection came from another region or neighbouring countries. In the 1990s, in a study in Dielmo, exposure to $P$. ovale was reported across all ages and perennial transmission of $P$. fal ciparum was also noted [17], therefore, it is possible that $P$. 


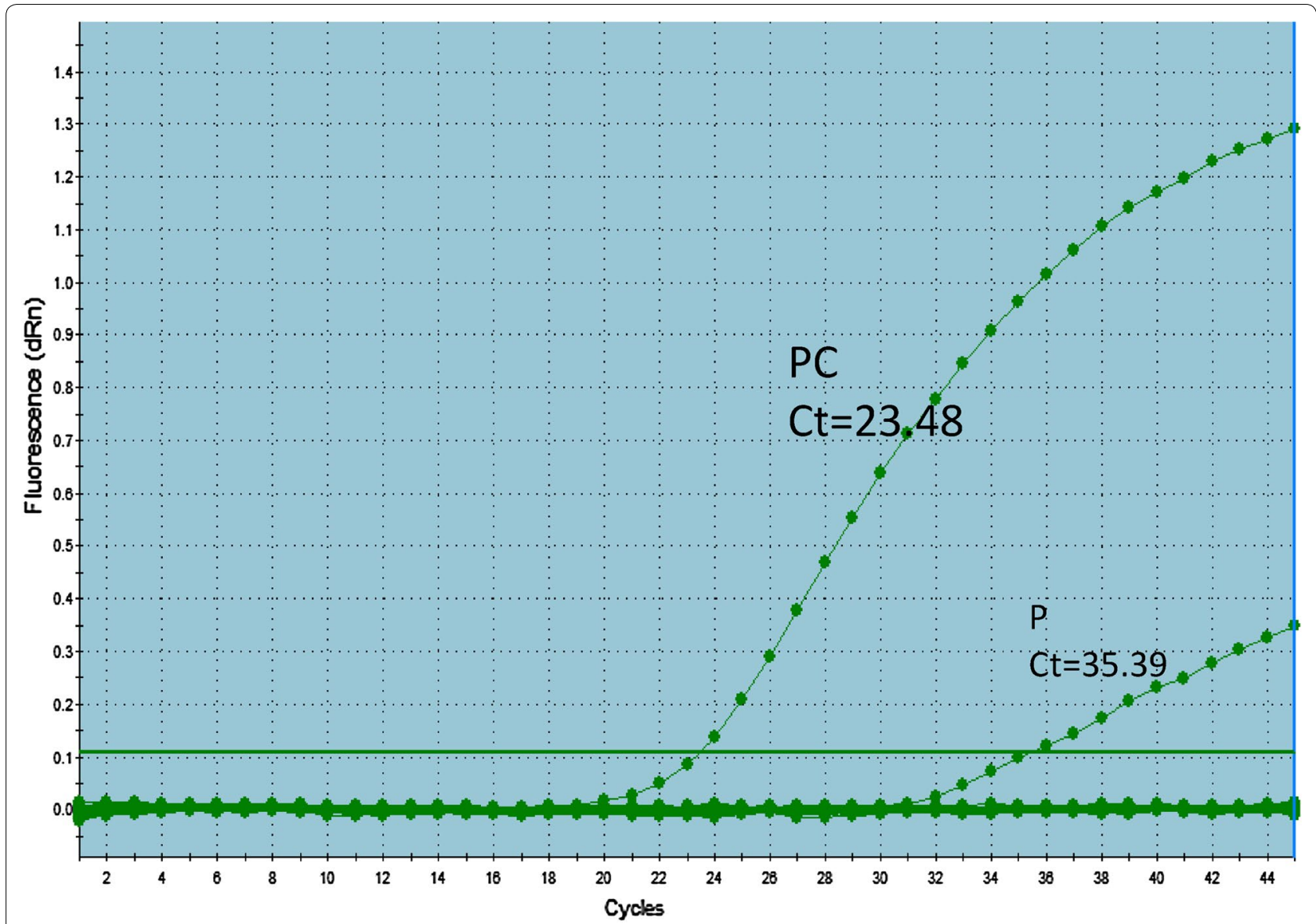

Fig. 2 Amplification plots for the real-time PCR targeting Plasmodium species 185 rRNA. P patient sample, PC positive control (know P. ovale sample)

falciparum cross immunity could protect against non-falciparum species [2]. However, in the West Central of Senegal like Diamniadio where malaria transmission is very low, this cross immunity might be low or none existing, making it easy to acquire malaria, including non-falciparum infections, as in this case report.

This present findings highlight the need to consider non-falciparum malaria infections in clinical settings both for the appropriate treatment of the infection and in order to further understand the epidemiology of malaria in the country. Plasmodium ovale infections present unique challenges because of the reported long latency period and the fact that two distinct species are known to exist [8]. In fact, the commonly used diagnostic tools in many endemic malaria regions, microscopy and RDT, are less sensitive when parasitaemia is very low and need expert microscopists or molecular assays to recognize uncommon species. In Senegal, $P$. falciparum is the most prevalent parasite detected when patients are suspected of malaria. Because of this, the national malaria control programme provides all health clinics of the country with HRP-2 based RDT, which are specific to $P$. falciparum. Therefore, it is possible that many cases of non-falciparum malaria infections are just not detected. This case report highlights the urgent need to develop standardized protocols capable of detecting all Plasmodium parasites in Senegal in order to achieve the malaria elimination agenda. In addition, although the existence of P. ovale hypnozoite remain controversial [18], they pose an important challenge in that they can cause relapse malaria which has great implications for treatment and transmission. Therefore, more species specific RDTs and field-usable molecular tools, such as the loop-mediated isothermal amplification (LAMP) are needed to assess the actual prevalence of $P$. ovale and other non-falciparum malaria parasites in Senegal and in other parts of Africa as previously suggested [19].

The current World Health Organization treatment guidelines recommend intravenous (IV) artesunate for the treatment of severe malaria due to all Plasmodium species [20]. In Senegal, since the national malaria control policies targets especially $P$. falciparum, ACT and quinine are the recommended and registered anti-malarials. The patient discussed in this case report was treated using IV quinine 


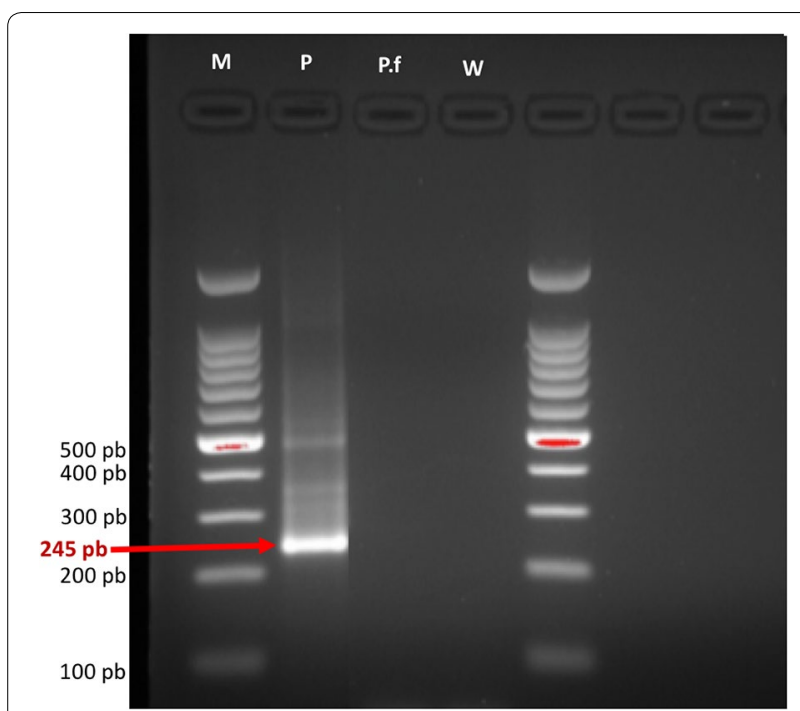

Fig. 3 Plasmodium ovale subtyping nested PCR targeting potra gene. In nest 1, primer pair PoTRAfwd3 and PoTRArev3 bind a 787-bp fragment. Using the internal primers PoTRAfwd5 and PoTRArev5, P. ovale wallikeri and P. ovale curtisi (245 to $355 \mathrm{bp}$ ) can be differentiated. The 245 fragments correspond to $P$. ovale wallikeri. $P$ patient sample, $W$ negative control (distilled water), $P f$ negative control ( $P$. falciparum), $M$ DNA size marker

followed by oral ACT, which according to the current Senegalese treatment guidelines, is still the treatment of choice for severe malaria in adult patients [21]. ACT has shown high efficacy in the treatment of non-falciparum malaria [22]. However, a recent longitudinal study conducted in Uganda using real-time PCR demonstrates persistence of infections of both $P$. falciparum and non-falciparum infections after ACT [19]. Importantly, primaquine, which is effective in the killing of both gametocytes and hypnozoites, is currently not registered in Senegal. Availability of primaquine in the health facilities will help to provide curative treatment for hypnozoites in $P$. ovale infected patients. Currently, the national malaria control programme plans to evaluate primaquine in the north of the country in an effort to end malaria in this region [21]. Also, chloroquine, which is the standard treatment of uncomplicated non-falciparum malaria, is no longer available in Senegal. In fact, since $P$. falciparum was considered resistant to chloroquine, this drug was withdrawn and national malaria control programme did not define treatment guideline for non-falciparum malaria explaining how neglected was the non-falciparum species in Senegal [21].

\section{Conclusion}

In summary, this case report demonstrates that $P$. ovale exists in West Central of Senegal and the prevalence is likely to be underestimated due to the diagnostic tools in place.
This case also highlights the fact that $P$. ovale malaria is not as benign as previously thought and that it is important to consider other non-falciparum malaria infections for appropriate patient care and for the success of the malaria control programme.

\section{Abbreviations}

ACT: artemisinin-based combination therapy; HRP: histidine rich protein; LAMP: loop mediated isothermal amplification; PCR: polymerase chain reaction; potra: P. ovale tryptophan-rich antigen; RDT: rapid diagnostic test; rRNA: ribosomal ribonucleic acid.

\section{Authors' contributions}

MAD, ASB and KD performed the microscopy examination. MAD collected clinical and biological data and drafted the manuscript; NWL performed the Rougemont real time PCR. MAD, AD, TN, LKS performed the potra genotyping experiment; MG, AG, MSY participated in the laboratory work. ASB, KD, NWL, VU and DN critically commented on the manuscript. All authors read and approved the final manuscript.

\section{Author details}

${ }^{1}$ Laboratoire de Parasitologie-Mycologie, Université Cheikh Anta Diop de Dakar, Avenue Cheikh Anta Diop, Fann, BP 5005, Dakar, Senegal. ${ }^{2}$ Malaria Branch, Division of Parasitic Diseases and Malaria, Center for Global Health, Centers for Disease Control and Prevention, Atlanta, GA, USA.

\section{Acknowledgements}

We are thankful to Youssou Mbargane Diop Hospital staff. We thank Mary Oguike and Colin Sutherland for their advice on subtyping protocol.

\section{Competing interests}

The authors declare that they have no competing interests.

\section{Availability of data and materials}

The datasets supporting the conclusions of this article are included within the article.

\section{Consent for publication}

Written informed consent was obtained from the patient for publication of this case report.

\section{Ethics approval}

The study received ethical clearance from the Ethic Committee of the Senegalese Ministry of Health. Informed consent was obtained from the patient.

Received: 21 July 2016 Accepted: 11 August 2016

Published online: 24 August 2016

\section{References}

1. Roucher C, Rogier C, Sokhna C, Tall A, Trape JF. A 20-year longitudinal study of Plasmodium ovale and Plasmodium malariae prevalence and morbidity in a West African population. PLoS ONE. 2014;9:e87169.

2. Collins WE, Jeffery GM. Plasmodium ovale: parasite and disease. Clin Microbiol Rev. 2005;18:570-81.

3. Trape JF, Tall A, Sokhna C, Ly AB, Diagne N, Ndiath O, et al. The rise and fall of malaria in a West African rural community, Dielmo, Senegal, from 1990 to 2012: a 22-year longitudinal study. Lancet Infect Dis. 2014;14:476-88.

4. Niang M, Thiam LG, Sow A, Loucoubar C, Bob NS, Diop F, et al. A molecular survey of acute febrile illnesses reveals Plasmodium vivax infections in Kedougou, southeastern Senegal. Malar J. 2015;14:281.

5. Sutherland CJ, Tanomsing N, Nolder D, Oguike M, Jennison C, Pukrittayakamee $\mathrm{S}$, et al. Two non-recombining sympatric forms of the human malaria parasite Plasmodium ovale occur globally. J Infect Dis. 2010;201:1544-50. 
6. Nolder D, Oguike MC, Maxwell-Scott H, Niyazi HA, Smith V, Chiodini PL, Sutherland CJ. An observational study of malaria in British travellers: Plasmodium ovale wallikeri and Plasmodium ovale curtisi differ significantly in the duration of latency. BMJ Open. 2013:3:e002711.

7. Oguike MC, Betson M, Burke M, Nolder D, Stothard JR, Kleinschmidt I, et al. Plasmodium ovale curtisi and Plasmodium ovale wallikeri circulate simultaneously in African communities. Int J Parasitol. 2011:41:677-83.

8. Tanomsing N, Imwong M, Sutherland CJ, Dolecek C, Hien TT, Nosten $F$, et al. Genetic marker suitable for identification and genotyping of Plasmodium ovale curtisi and Plasmodium ovale wallikeri. J Clin Microbiol. 2013:51:4213-6.

9. Rougemont M, Van Saanen M, Sahli R, Hinrikson HP, Bille J, Jaton K. Detection of four Plasmodium species in blood from humans by $18 \mathrm{~S}$ rRNA gene subunit-based and species-specific real-time PCR assays. J Clin Microbiol. 2004;42:5636-43.

10. Mueller I, Zimmerman PA, Reeder JC. Plasmodium malariae and Plasmodium ovale - the 'bashful' malaria parasites. Trends Parasitol. 2007:23:278-83.

11. Lau YL, Lee WC, Tan LH, Kamarulzaman A, Syed Omar SF, et al. Acute respiratory distress syndrome and acute renal failure from Plasmodium ovale infection with fatal outcome. Malar J. 2013;12:389.

12. Strydom KA, Ismail F, Frean J. Plasmodium ovale: a case of not-so-benign tertian malaria. Malar J. 2014;13:85.

13. Lemmerer $R$, Unger $M$, Vossen $M$, Forstner $C$, Jalili $A$, Starzengruber $P$, et al. Case report: spontaneous rupture of spleen in patient with Plasmodium ovale malaria. Wien Klin Wochenschr. 2016;128:74-7.
14. Faye FB, Spiegel A, Tall A, Sokhna C, Fontenille D, Rogier C, et al. Diagnostic criteria and risk factors for Plasmodium ovale malaria. J Infect Dis. 2002;186:690-5.

15. Rojo-Marcos G, Rubio-Muñoz JM, Ramírez-Olivencia G, García-Bujalance S, Elcuaz-Romano R, Díaz-Menéndez M, et al. Comparison of imported Plasmodium ovale curtisi and P. ovale wallikeri infections among patients in Spain, 2005-2011. Emerg Infect Dis. 2014;20:409-16.

16. Lacerda MV, Mourão MP, Coelho HC, Santos JB. Thrombocytopenia in malaria: who cares? Mem Inst Oswaldo Cruz. 2011;106(Suppl 1):52-63.

17. Faye FB, Konaté L, Rogier C, Trape JF. Plasmodium ovale in a highly malaria endemic area of Senegal. Trans R Soc Trop Med Hyg. 1998;92:522-5.

18. Richter J, Franken G, Mehlhorn H, Labisch A, Häussinger D. What is the evidence for the existence of Plasmodium ovale hypnozoites? Parasitol Res. 2010;107:1285-90.

19. Betson M, Sousa-Figueiredo JC, Atuhaire A, Arinaitwe M, Adriko M, Mwesigwa G, et al. Detection of persistent Plasmodium spp. infections in Ugandan children after artemether-lumefantrine treatment. Parasitology. 2014:141:1880-90.

20. WHO. Management of severe malaria. Geneva: World Health Organization; 2012.

21. Programme national de lutte contre le paludisme (PNLP). Cadre stratégique national de lutte contre le paludisme au Sénégal 2014-2018; 2014.

22. Mombo-Ngoma G, Kleine C, Basra A, Würbel H, Diop DA, Capan M, et al. Prospective evaluation of artemether-lumefantrine for the treatment of non-falciparum and mixed-species malaria in Gabon. Malar J. 2012;11:120.

\section{Submit your next manuscript to BioMed Central and we will help you at every step:}

- We accept pre-submission inquiries

- Our selector tool helps you to find the most relevant journal

- We provide round the clock customer support

- Convenient online submission

- Thorough peer review

- Inclusion in PubMed and all major indexing services

- Maximum visibility for your research

Submit your manuscript at www.biomedcentral.com/submit

(OioMed Central 